\title{
Communication Skills in Handling Hoteliers' Grievances
}

\author{
Ronel M. Sapungan ${ }^{1}$, Romel M. Aceron ${ }^{1}$, Lucina S. Lat ${ }^{1}$, Gea Micquelle M. Angeles ${ }^{1}$, Jonil G. Gaspacho ${ }^{1}$ \& \\ Maica Angela P. Legion ${ }^{1}$ \\ ${ }^{1}$ Batangas State University JPLPC-Malvar, Philippines \\ Correspondence: Ronel M. Sapungan, College of Accountancy, Business, Economics, and International \\ Hospitality Management, Batangas State University JPLPC-Malvar, Philippines. Tel: 639-217-490-578.
}

Received: December 24, 2018; Accepted: January 9, 2019; Published: January 11, 2019

\begin{abstract}
Communication skills in handling hoteliers' grievances have been a great concern in hospitality industry. Hence, this descriptive research was conducted to assess the extent of communication skills of the respondents in handling grievances relative to commissive, declarative, expressive, and representative. It determined the demographic profile of the respondents in terms of age, gender, civil status, status of employment, position, and role of committee on grievances. It also determined if there was a significant difference on the respondents' assessment of communication skills handling hoteliers' grievances when grouped according to their profile. It was conducted to provide input to have effective communication skills in handling grievances. The researchers used descriptive research method in order to assess the communication skills in handling hoteliers' grievances. There were no sampling techniques used in the study. The researchers limited their respondents to fifteen hoteliers and members of grievance committee. The survey questionnaire served as data gathering tool while frequency, weighted mean, and ANOVA were used to test the communication skills in handling grievances. The researchers found out that majority of the grievance committee members in the selected hotel establishments were in the age of 24-38, male, married employee with a regular permanent job. The study found out that there was no significant difference on the assessment of the respondents when they were grouped according to their profile. It further revealed communication skills of members in handling hoteliers' grievances was highly observed. Based on the findings, the researchers proposed a course of action as input for effective communication skills in handling grievances.
\end{abstract}

Keywords: communication skills, hoteliers' grievances, commissive, declarative, expressive, representative

\section{Introduction}

Communication is one of the most important aspects of human's life. It is what connects people as human being with their environment. Without it, society cannot function well, whether it is face-to-face conversation across a dinner table or video conferencing in international boundaries. It is used for people to understand each other. It helps them to easily deal with problems. Poor communication can result in misunderstanding and mistrust. Communication involves a transaction: a person wants to talk to someone because one needs something. Communication is an intricate process of sharing ideas, thoughts, and information (Flores, 2016).

Sapungan, et al. (2018) explain that communication is what connects people as human beings, and it is also one of the most important concern in life. People can express their feelings and thoughts by the help of communication; it is also a way of sharing beliefs and culture to one another. In today's life good communication skills is vital all over the world and having it can lead someone to success in any career.

Individuals living in the community have to communicate with people in order to share their feelings with the other members of the society and to live a balance life (Ergun, 2009). The communication which is one of the most important elements necessary for people to adapt to the environment must be technically known by individuals in every profession and they must develop their skills in this regard (Serkan, 2014).

Good communication skills are a learned art and not a natural skill so one should consider training to enhance staff skills. Excellent communication skills enhance guest experience as it conveys that you are listening to your guests, valuing their feedback and conveying clear messages. Not only does the staff need to communicate successfully with the guests but also with other department employees. Few of the staff members might be able to speak in manageable English but those who do not have English as their first language suffer due to their inability and fail to understand simple instructions and information. Department heads often face problems such as failing to communicate well with guests which may result in lack of confidence among the staff members, failing to process 
written documents such as emails, reports and other collaterals, and failing to understand the hotel management software hotels use these days.

The results of great communication skills are improved customer service, better understanding of the instructions from supervisors among the staff members, great understanding of the latest technology used by hotels, boosted confidence to approach guests, and positive attitude towards the workplace and higher level of understanding between the department heads. As stated above, effective communication skill is a learned art and not a natural skill so it doesn't mean that the relevant skills cannot be developed (Pathak, 2014).

Communication is an essential to teamwork, not only does it build and maintain relationships, but workplace communication also facilitates innovation. Employees who feel comfortable about communicating will have new ideas at an exceptional rate. Without workplace communication, there will be several problems. Such as; lack of standard communication problem, communication barriers, mixing work, and personal communication, misinterpretations and assumption, poor listening skills, lack of factual communication, failure to disperse communication, privacy, and attitude (Frost, 2008).

Grievance is an important aspect of communication. As means of communication, it is used to connect a negative effect and causes of distress and unsatisfactory working condition. It is considered as the most common hindrance in achieving effective communication.

In the hospitality industry, grievance management is not a new subject, and it's in the most persistent area. While running a company, people work in the different cultures as compared to rest of the society, in which they adopt perception attitude and behavior towards the work culture. Hospitality is related to serving the customers and offers them "feel-good-effect" With the increasing competition the hotel management should try to rectify the issues which are faced by the employees. Therefore, grievances often deteriorate the human relations and include dissatisfaction that is often experienced by the employees and the same impact the organization performance both directly and indirectly. Any real feeling related to personal injustice, which is concern by the employee's relationship is known as grievances (Adams and Figueroa, 2013).

According to Dessler (2013), the grievance can grow out of bad relationship at workplace between employee and employer or supervisor, especially when they feel that they are not being treated fairly. Workers grievances are commonly based on alleged violation of an existing rights or an unfair treatment by management. It is important to identify such conflicts or discomforts among employees and try to resolve them before they become a dispute. Thus, the key concern is to determine whether the level of awareness is higher or lower among employees regarding grievance procedure through which line manager or the employer tries to resolve such complaints or issues before they become disputes. Thus, clear and transparent framework is provided by grievance procedure to deal with problems or complaints, concerns which are raised by employees in the course of their employment.

Handling grievances requires constant communication with employees to minimize any confusion and misunderstanding. Without frequent communication may cause a high employment turnover. Added to the cause is a depressed workforce with low productivity and high absenteeism rate. In handling general grievances, communication is key and organizations can include the following information in the communication process.

Grievances are usually based upon a violation of a term in an employment contract, or a violation of a past practice. A past practice grievance usually arises when management unilaterally, and without notice to the union, changes an established procedure or disciplines a worker for following a past practice. In law, this is a compliant due to injury, injustice, or wrong. According to US Legal, in Human Resource, there is a specific complaint; it is a formal employee notice of dissatisfaction, pay, expectations, work conditions, other employment aspects, or an alleged violation of a collective bargaining agreement are all examples of subjects for a grievance.

Along this contention, the researchers aimed to know if there was a proper usage of communication skills in handling hoteliers' grievances to employer-employee relationship. The researchers wanted to know how these communication skills in handling hoteliers' grievance would help them in settling grievances, complaints, and other labor and industrial disputes. They also wanted to establish satisfaction among employees at the workplace as well as their personal growth within themselves as a quality of life, through a proposed input which would be bases on the findings of the study.

Because the researchers wanted to propose courses of action as input to strengthen the effectiveness of communication skills in handling grievances, the study will help educational institutions consider the input as their reference or guide in creating their program that will help instructor of Hotel and Restaurant Management (HRM) to identify the best communication and grievance handling principles to be learned by the students. This study would guide the management in using proper communication to lessen grievances in business operations. Through 
this, managers can acquire information, ideas, and strategies with regard to the handling of employees in order to attain a great and stable operation and successful establishment of their own. It would help employee and community be aware about their performance in the jobs that are evaluated and assessed. This would also help them realize the importance of being competent in terms of communications and being rational in handling grievances to improve themselves. This serves as a guideline for those who are willing to build their own business. It would help prospective applicants decide which company they will choose for work. It would help them build their relationship with their future employer through communication and grievance handling. It would serve HRM students as a guide regarding the proper use of communication and grievance handling. They can apply what they have learned in this study to their future career or job. Finally, this study will benefit and help the future researchers as they conduct similar study using other relevant variables.

\subsection{Objectives of the Study}

The researchers tried to determine the communication skills of members in handling hoteliers' grievances. Specifically, it aimed to achieve the following objectives: to determine the profile of the grievance committee members in terms of age, gender, civil status, position, status of employment, and role on grievance committee; to describe and analyze the extent of respondents' communication skills in handling grievances relative to commissive, declarative, expressive, and representative; to assess the significant difference on the respondents' assessment of communication skills handling hoteliers grievances when grouped according to their profile; and to provide an input to strengthen the effectiveness of communication skills in handling grievances.

\subsection{Theoretical Framework}

This theoretical framework presented below served as the basis of the researchers in formulating the structure of this study. Searle's Speech Act Theory as clearly described by Aceron (2015) in his study deals with the person or individual communication skills as commissive, declarative, expressive, and representative.

According to Richards and Schmidt (Aceron, 2015), speech act is an utterance as a functional unit in communication. A speech act which is performed indirectly is sometimes known indirect speech act—often felt to be more polite ways of performing certain kinds of speech act, such as request and refusals (p. 2). Speech Act is classified as commissive, declarative, expressive, and representative (p. 3). These classifications directly answer to the objective of the study of examining and describing communication skills in handling grievances as conveyed by hoteliers of select hotels in Lipa City and Sto. Tomas, Batangas.

Commissive is a speech act that commits the speaker to doing something in the future. As to declarative, it is a speech act which changes the state of affairs in the world, depending on the style, form, and purpose of the speaker. A speaker expresses his feelings and attitudes about something - a speech act known as expressive. Lastly, the representative is a speech act which describes states or events like an assertion, a claim, and a report.

Searle's Speech Act Theory has an important bearing on the present study as this describes the four (4) important classification of speech act - commissive, declarative, expressive, and representative as essential variables to determine the communication skills of hoteliers in handling grievances in the workplace.

Operational Framework

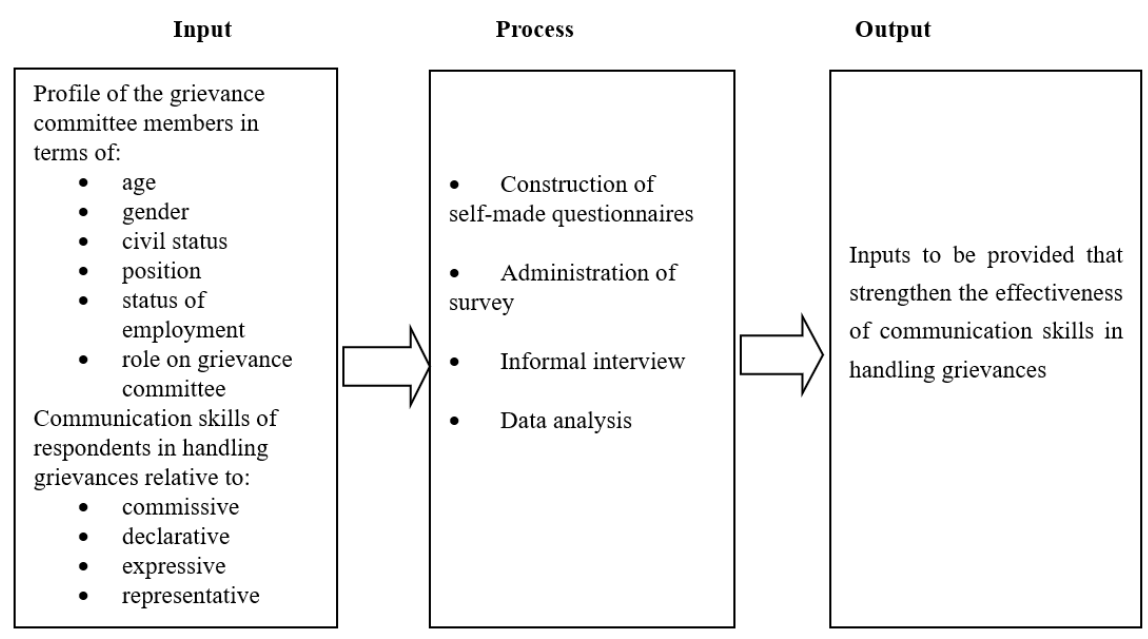

Figure 1. Conceptual Paradigm of the study 
The study follows the Input-Process-Output (IPO) Model as its operational framework. The input frame includes the profile of the grievance committee members in terms of age, gender, civil status, position, status of employment, and role of committee members on grievance. This research also intended to assess the communication skills of respondents in handling grievances as to commissive, declarative, expressive and representative. Furthermore, the process frame contains the method and procedure of the study. It includes construction of questionnaires to obtain the necessary data. It also contains administration of survey, informal interview, and data analysis. Following the assessment and analysis, the researchers worked on the improvement of the proper communication skills in handling hoteliers' grievances through proposed course of action as input of the study. This program served as the output of the study

\subsection{Research Hypothesis}

This study was guided by the null hypothesis that there was no significant difference on the communication skills in handling hoteliers' grievances of the respondents when group according to their profile.

\section{Methods}

\subsection{Research Design}

The researchers used the descriptive method in this study. This method gathered information that could be used in identifying the most suitable communication skills in handling grievances to be used in different hotels. The researchers examined how the establishment handles grievances in the workplace and how the management communicates with their employees.

The descriptive method of research, as opposed to an experimental or normative method develops knowledge by describing observed situations, events, and objects (Robison, 2010). Kothari (2008) contends that a descriptive research design is suitable where the study needs to draw conclusions from a larger population. This helped in forming the current position of the population under the study.

The researchers performed the study based on the data gathered from the survey. The researchers also collected data through reading informative source about the communication and grievance handling.

\subsection{Respondents of the Study}

The respondents were those who employed as hoteliers and members of grievance committee in Microtel Sto. Tomas, San Tomas Suites, and La Corona Lipa. All members of the grievance committee were included in the study, thus a census survey. A target population as a specific proportion of the entire population was narrowed to achieve the research objectives. The respondents of the study were 15 hotel staff of three selected hotels.

Based on the availability of respondents in constraint, only three (3) were identified the commission of the committee members, a total of 15 respondents; four (4) from La Corona Hotel, six (6) from Microtel, and five (5) from San Tomas Suites.

The researchers were not able to target a total population of the three (3) hotels because some of the respondents did not comply to answer the questionnaire and the establishment did not allow their employee to answer it because of their hectic work.

\subsection{Sampling Design}

There was no sampling technique used since the total number of the members of grievance committee of Microtel Sto. Tomas, La Corona, San Tomas, and NDN Grand Hotel were considered as the respondents of the study. They are 15 grievance committee member respondents utilized in this study.

\subsection{Data Gathering Instrument}

The researchers gathered data mainly from books, articles, published thesis, and from the internet. The researchers prepared and collected all reliable sources and selected the most important information regarding communication and grievance handling.

Researchers used a self-constructed survey questionnaire composed of two parts. The first part contained the profile of the respondents which includes age, gender, civil status, position, and status of employment. The second part consisted of communication skills in handling hoteliers' grievances as to commissive, declaration, expressive, and representative.

In the self-constructed questionnaire, the researchers also used a four (4) point rating scale depending on how employee handles grievances. To be able to determine the communication skills of hoteliers in handling grievances, the following mean ranges and their corresponding verbal interpretations were used to interpret the computed weighted mean and composite mean. 
Before the final distribution, the questionnaire was given to language gurus, research experts and other experts in the field for validation purposes. The researchers conducted a reliability test in Club Balai Isabel and Hotel Gregorio to ensure that their questions were reliable before they conducted actual survey. After the conduct of presurvey to determine the reliability of the questionnaire, the researcher distributed the questionnaires to the targeted respondents.

For the interpretation of weighted mean, the researchers made numerical values with corresponding verbal interpretation to assess the respondents' response. To assess each item in the research made questionnaire the respondents were requested to rate each item on a four point Likert's scale with its mean ranges corresponding verbal interpretation.

\begin{tabular}{lll}
\hline & Numeral Rating Value & Mean Ranges Verbal Interpretation \\
\hline $\mathbf{4}$ & $3.50-4.00$ & Highly Observed (HO) \\
$\mathbf{3}$ & $2.50-3.49$ & Observed (O) \\
$\mathbf{2}$ & $1.50-2.49$ & Moderately Observed (MO) \\
$\mathbf{1}$ & $1.00-1.49$ & Not Observed (NO) \\
\hline
\end{tabular}

\subsection{Research Procedure}

In order to conduct this study, the researchers considered a series of steps and procedures in gathering the data. The researchers read some books and articles about their topic. The researchers sought some advices from the experts. The researchers first formulated the research topic, then the researchers started gathering literature to support and enrich the study. With regard to the questionnaire, the researchers used a self-constructed type of questionnaire. The researchers read books and another thesis as a guide for them to write the questionnaire.

The questionnaire was checked for the accuracy of the questions. After some revisions, the questionnaire was presented to experts to validate the questionnaire and to determine whether the questions and statements were stated correctly. In the final draft of the questionnaires, the researchers consulted the statistician to test the reliability of the questionnaire.

After the validation and reliability testing, the researchers write a letter with the proper notation from the adviser. The letter included the most respective request to allow the researchers to ask for the respondents support and cooperation by answering the questionnaire.

For the actual survey, the researchers distributed the questionnaires to the respondents. The researchers personally conversed with the respondents and guided them in answering the questionnaire; they immediately collected the answered questionnaires from the respondents.

After the retrieval of the questionnaires, the researchers tallied the responses and group them accordingly. The grouped data were presented to the statistician and left for computation using the appropriate statistical tools. Thereafter, the researchers analyzed and interpreted the results. The researchers noted of the important findings and formulated appropriate conclusions and recommendations.

\subsection{Statistical Treatment of Data}

After collecting the data from the respondents, these were tabulated, tallied and analyzed. The gathered data were subjected to the following statistical treatments: Frequency and Percentage, This was used to determine the profile of the employee respondents; Weighted Mean and Composite Mean, this was used to determine the overall average of the respondents' experience on communication and grievance handling in hotels; and Analysis of ance (ANOVA), this was used to determine the significant difference between the employee communicumun and grievance handling when grouped according to their profile.

\section{Results}

The data gathered through different research instruments are presented and discussed thoroughly in this section. The inputs include profile of the respondents and their communication skills in handling grievances. The presentation of discussion and interpretation follow the logical sequence of the specific problems stated in the first part of this study.

\subsection{Profile of the Grievance Committee Members}

The succeeding tables present the profile of the respondents in terms of age, sex, civil status, position and status of employment. 


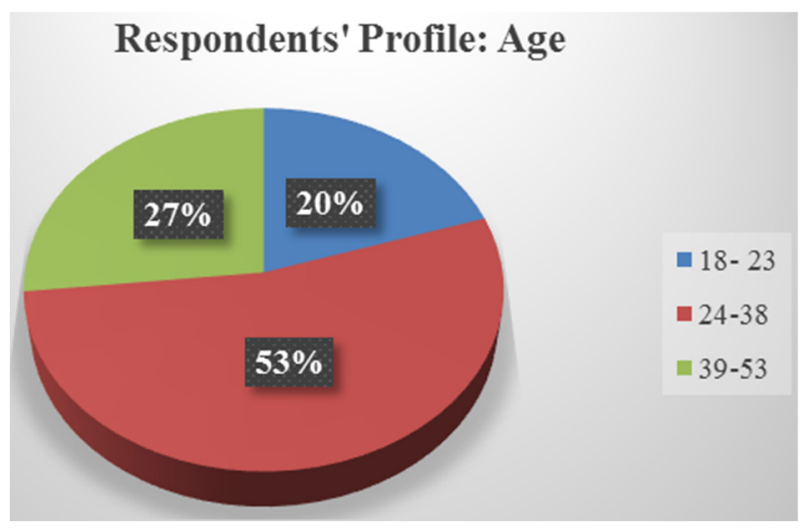

Figure 2. Distribution of the Grievance Committee Members in terms of Age

As presented in Figure 2, majority of the respondents belonged to the age group of 24-38 years old having a frequency of eight and a percentage of 53. The second highest number of respondents belonged to the age group of 39-53 years old, having a frequency of four and a percentage of 27 for each age group and lastly the age of 1823 years old having a frequency of three and a percentage of 20 was the age group that had a least number of respondents.

It can be explained that a greater percentage of the respondents were in the age group of 24-38 years old. This was probably due to fact that employees in this generation are physically fit, productive, creative, and flexible to adapt from changes especially in this modern society. They can also perform and do their task well. The age of 18-24 years old had the least number on the total population, it was because employees of this age were so young and new in the field and had least experience in handling grievances.

It can be viewed that majority of the employees from Microtel, San Tomas and La Corona belonged to the younger age group. They chose to hire young skilled employees who can work faster and can be adaptable to change rather than the old employees.

Armstrong (2008) explained that young adults are preferred to accomplish many responsibilities including finding a home and mate, establishing a family or circle of friends and or getting a good job.

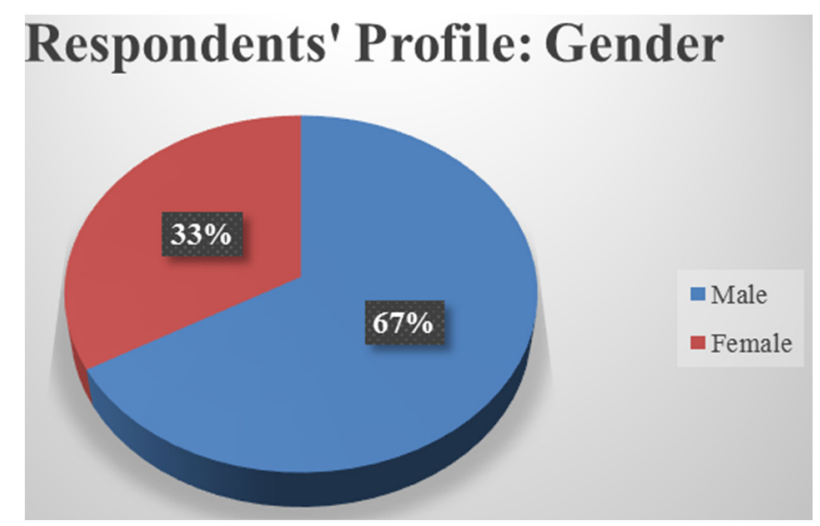

Figure 3. Distribution of the Grievance Committee Members in terms of Gender

As presented in Figure 3, majority of the respondents were male with a frequency of ten and a percentage of five while female respondents have a frequency of five and a percentage of 33 . This means that most of the respondents employed in the hospitality industry were male because they were flexible enough to do the task since they can perform well and they can do more physical tasks.

It can be viewed the reality that Microtel, San Tomas and La Corona hire more male because males can do heavy works as needed in this field. And also, male staff is more capable in terms of lifting heavy equipment or furniture used in production and operation. 
The result got support from the study of Heidi (2008), stating that men were over 30 percent stronger than women, especially in the upper body. Although many feminists cannot face this fact, females simply do not have the strength or endurance necessary in the workplace. This only proved that a male is bolder than female. The males can perform any hard task; which female cannot perform.

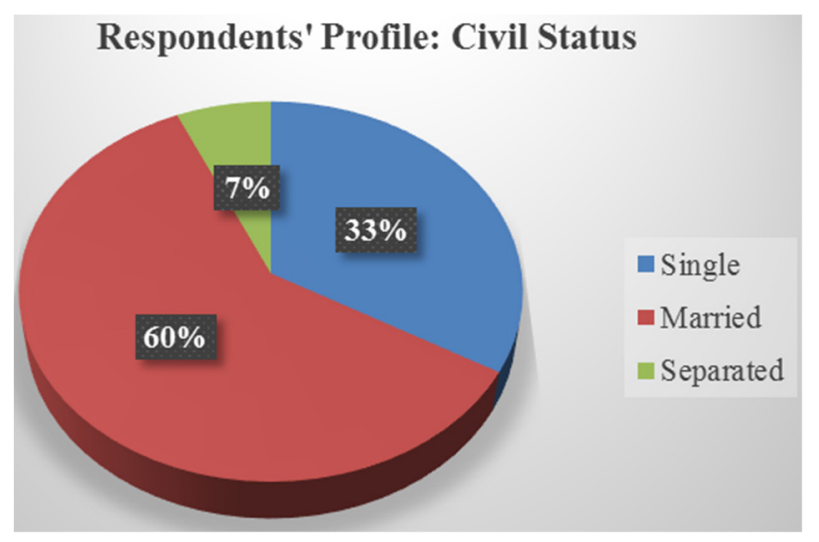

Figure 4. Distribution of the Grievance Committee Members in terms of Civil Status

As presented in Figure 4, majority of the respondents were married with a frequency of nine which yield a percentage of 60. It was followed by the single employees with a frequency of five and a percentage of 33 . However, only one respondent was separated which generated a percentage of seven. The results revealed that there were more married respondents, since there were more employees belong to the young adults or the age bracket of 2438 years old. There was only one respondent who was separated it was because the Filipino culture values the importance of marriage that is why majority of the respondents are married and there is just one who is separated.

The finding is backed up by the study of Stanrock (2008); he discussed the different point of view or single individuals and married couples in terms of their work. He stated that married workers prioritize their job stability and at the same time they are more responsible and motivated on their work since they have an obligation to provide a better life for their family while single do not give importance on job stability because most of them want knowledge, familiarity and chances from other industries.

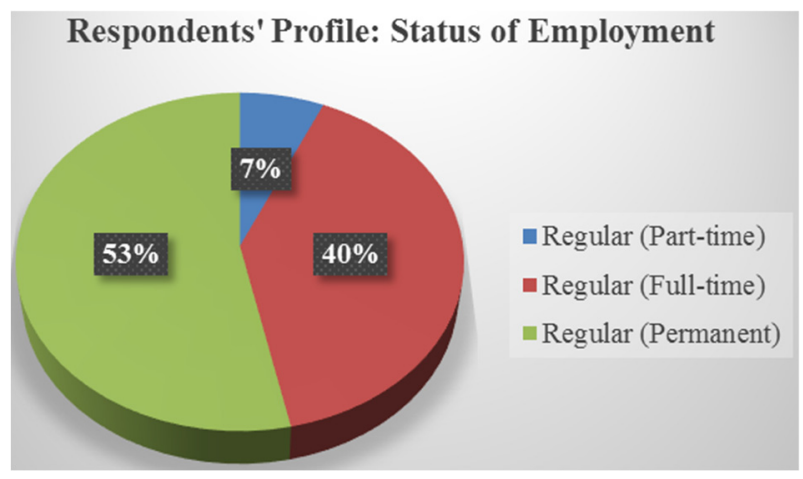

Figure 5. Distribution of the Grievance Committee Members in terms of Status of Employment

As indicated in the table above, a large number of respondents occupied regular permanent position with a frequency of eight and a percentage of 53. Meanwhile, some respondents were regular full-time with a frequency of six and a percentage of 40 . However, only one respondent was regular part-time having a frequency of one with equivalent percentage of seven. It is an indication that the respondents were highly dominated by the employees with employment status of regular permanent.

It represents that most of the employee in Microtel, San Tomas and La Corona were regular permanent staff because their employees were more likely able to do their job effectively if they know they had a measure of job security, long-term prospects, and an opportunity to build relationship with other employee. There was only one regular part-time respondent it was because part-time employees often hold more than one job, meaning possible competition for time and loyalty. In addition, part-time employees are possibly creating a turn over problem. 
According to Mill (2008), the permanent employee is also called regular employee. It means that employed without a definite period and the employer may not terminate his services except for a just cause or when authorized by law.

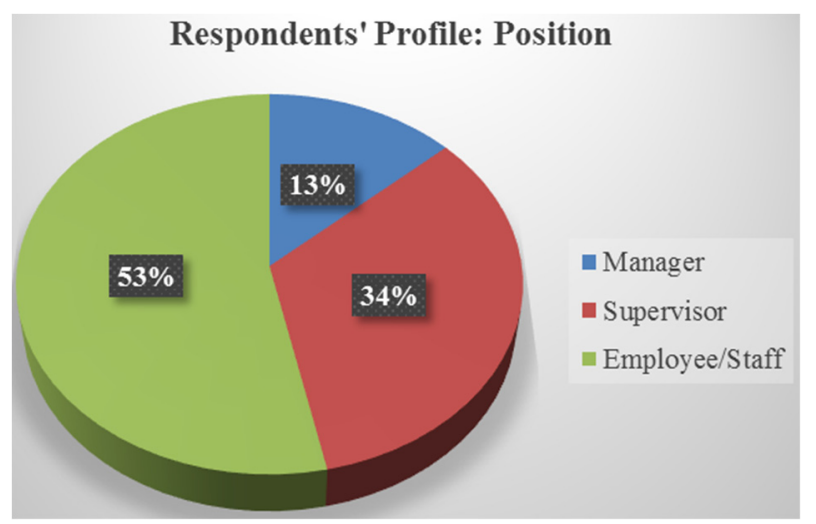

Figure 6. Distribution of the Grievance Committee Members in terms of Position

As presented in the figure above, majority of the respondents occupied employee/staff position with a frequency of eight and a percentage of 53. Meanwhile, some respondents are supervisor with a frequency of five and a percentage of 33. However, only two respondents are manager having a frequency of two with equivalent percentage of 14 . This means that majority of the respondents who answered on the survey questionnaire were the employee/staffs of the hotel because they had greater number than managers and supervisor. Employees had greater number than manager and supervisor was because they do more task or operation within the establishment. There were two respondents who were manager it was because that it is the standard position in the hospitality industry; if there is a lot of manager they will be having their conflicts in terms of idea and decision.

According to Job Monkey (2018), working in a hotel industry can be fun and exciting, depending on the hotel and your position. There are lot of jobs to choose from, at each hotel, though, similar positions need to be filled. There are usually management employees, maintenance employees, kitchen and wait staff, housekeeping staff members, front desk employees, and the staff who purchase supplies, perform accounting work, and provide similar support.

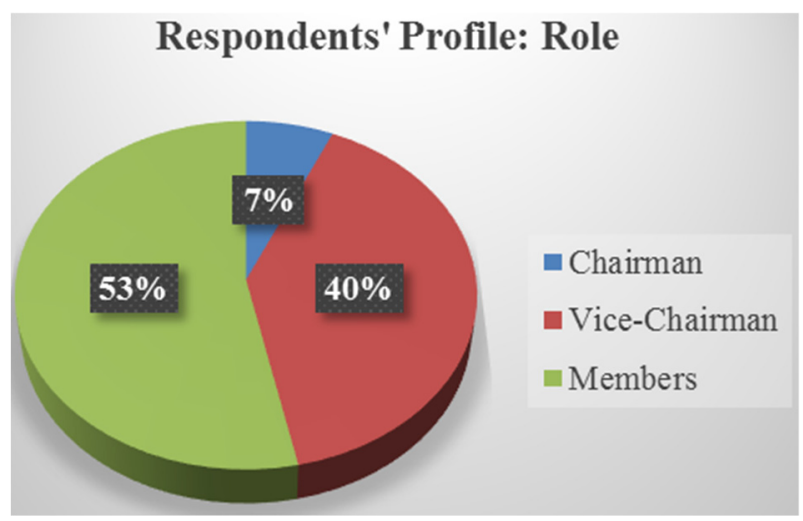

Figure 6. Distribution of the Grievance Committee Members in terms of Role

As indicated in Figure 6 above, a large number of respondents occupied members' position with a frequency of eight and a percentage of 53. Meanwhile, some respondents were vice-chairman with a frequency of six and a percentage of 40. However, only one respondent was chairman having a percentage of seven. It is an indication that majority of the respondents are members of the grievance committee because the role of grievance committee is to ensure that every complaint will be resolved fast and to avoid the conflicts. It was also the one who was responsible for making standards and protocols on how to handle grievances. There is only one grievance committee chairman it is because the chairperson makes all members value and the one who makes final decision. 
The study got support from the article of Grievance Job Description which explained that that there shall be not more than 18 members not less than 12 members of the grievance committee who are active members of the board. Appointment shall be made by the board of directors from those who apply and meet the criteria.

\subsection{Assessment on the Communication Skills in Handling Hoteliers Grievances}

The succeeding tables present the data gathered through the questionnaire accomplished by the respondents. The data presented herein concern on the assessment on the communication skills in handling hoteliers' grievances.

3.2.1 Commissive. This is one of the factors used by the researchers in assessing the communication skills in handling hoteliers' grievances. Table 1 presents the assessment on the communication skills in handling hoteliers grievances in terms of Commissive.

Table 1. Communication Skills in Handling Hoteliers Grievances as to Commissive

\begin{tabular}{lll}
\hline Statements & Weighted Mean & Verbal Interpretation \\
$\begin{array}{l}\text { 1. The grievance committee members have the ability to } \\
\text { maintain confidentiality of sensitive and personal information. }\end{array}$ & 3.67 & Highly Observed \\
$\begin{array}{l}\text { 2. The grievance committee members have willingness to do } \\
\text { ongoing committee to work on a volunteer basis. }\end{array}$ & 3.67 & Highly Observed \\
\hline $\begin{array}{l}\text { 3. Managers/supervisors are responsible to make future actions } \\
\text { in order to manage guest complaints. }\end{array}$ & 3.60 & Highly Observed \\
\hline $\begin{array}{l}\text { 4. Managers/supervisors engage to make solution for grievance } \\
\text { complaints. }\end{array}$ & 3.60 & Highly Observed \\
\hline $\begin{array}{l}\text { 5. The employees raise and deal with issues promptly and not } \\
\text { unreasonably delay meetings, decisions, or confirmation of } \\
\text { those decisions. }\end{array}$ & 3.47 & Observed \\
\hline $\begin{array}{l}\text { 6. The employees address the issues promptly before they reach } \\
\text { the stage of becoming a formal grievance issue. }\end{array}$ & 3.53 & Highly Observed \\
\hline Composite Mean & $\mathbf{3 . 5 9}$ & Highly Observed \\
\hline
\end{tabular}

As shown in the table, the assessment of the respondents' with regard to their observation in the area of commissive are found highly observed as reflected in the statements "The grievance committee members have the ability to maintain confidentiality of sensitive and personal information" and "The grievance committee members have willingness to do ongoing committee to work on a volunteer basis". Both statements got the highest weighted mean of 3.67 with verbal interpretation of "highly observed". This implies that the establishment or the hotels are securing the confidentiality about the information and they are focusing to find quick solution for grievance complaints within the establishment and willing to do a task or work in a volunteer basis. This is followed by the statement "Managers/supervisors are responsible to make future actions in order to manage guest complaints" and "Managers/supervisors engage to make solution for grievance complaints", which obtained a weighted mean of 3.60 with an interpretation of "highly observed". The finding implies that the management of the hotels makes future actions on how to handle guest complaints. The table also reveals that the statement which garnered the last rank was the statement "The employees raise and deal with issues promptly and not unreasonably delay meetings, decisions, or confirmation of those decisions" as obtained a weighted mean of 3.47 with an interpretation of "observed". Overall, the assessment on communication skills in handling hoteliers' grievances as to commissive garnered a 3.59 composite mean and has a verbal interpretation of "highly observed".

The findings are supported by the article of Anastasia (2017) which explained that to hear an employee complaining about having a hard time with their tasks, or even day to day interaction with other employees, is already something that happens in many different companies. How they handle these complaints can easily mean the difference between being the super boss everyone wants to work for and the dictator responsible for everybody's problems. Stories like those have been retold over and over as time went by, even as corporate and workplace cultures have evolved. Employees who complain against their employers were, more often than not, viewed as ungrateful, showing no gratitude because the act seems dangerously close to "biting the hand that feeds them". 


\subsubsection{Declarative}

This refers to the words and expressions that the world via utterances such as betting, naming, baptizing, and marrying (Searle, 1969). Table 2 presents the assessment on the communication skills in handling hoteliers grievances in terms of Declarative.

Table 2. Communication Skills in Handling Hoteliers Grievances as to Declarative

\begin{tabular}{lll}
\hline Statements & Weighted Mean & Verbal Interpretation \\
\hline $\begin{array}{l}\text { 1. Grievance committee members have formal written notice } \\
\text { for non-civil service employees/supervisors/managers about }\end{array}$ & 3.47 & Observed \\
the complaints/grievance filed in the office. & & \\
$\begin{array}{l}\text { 2. Grievance committee members communicate details of } \\
\text { grievance procedures to the concerned person involved. }\end{array}$ & 3.47 & Observed \\
$\begin{array}{l}\text { 3. Managers/supervisors have orientation of grievance } \\
\text { procedures in new employees. }\end{array}$ & 3.53 & Highly Observed \\
$\begin{array}{l}\text { 4. Managers/supervisors can manage grievance complaints } \\
\text { according to the grievance procedures. }\end{array}$ & 3.60 & Highly Observed \\
$\begin{array}{l}\text { 5. The employees are well informed about grievance } \\
\text { procedures. }\end{array}$ & 3.47 & Observed \\
6. The employees can handle and manage guest complaints. & 3.40 & Observed \\
\hline Composite Mean & $\mathbf{3 . 4 9}$ & Observed \\
\hline
\end{tabular}

As shown in the table, the assessment of the respondents' with regard to their observation in the area of declarative are found observed as reflected to the statement "Managers/supervisors can manage grievance complaints according to the grievance procedures." has the highest weighted mean 3.60 with an interpretation of " highly observed" followed by the statement, "Managers/supervisors have orientation of grievance procedures in new employees" with a weighted mean of 3.53 with an interpretation of "highly observed". This implies that managers and supervisors have a formal discussion in grievance procedure towards their employees and they can also manage the grievance complaints. The table also revealed that the statement which garnered the last rank was the statement "The employees can handle and manage guest complaints." as obtained to its weighted mean of 3.47 with an interpretation of "observed". Overall, the assessment on communication skills in handling hoteliers' grievances as to declarative garnered a 3.49composite mean and has a verbal interpretation of "observed". The finding revealed that the hotel management focuses on how to manage or resolve the grievance complaints within the establishment.

The result got support from Hartigan (2013) who mentioned that taking the appropriate action can only be done after hearing a customers' problems, understanding their feelings and combining it with a sincere apology

3.2.3 Expressive. This is a kind of speech act that states what the speaker feels. Apologizing, thanking, congratulating, condoling, greeting are such examples of expressive speech (Searle, 1969). Table 3 presents the assessment on the communication skills in handling hoteliers' grievances in terms of Expressive.

Table 3. Communication Skills in Handling Hoteliers Grievances as to Expressive

\begin{tabular}{lll}
\hline Statements & $\begin{array}{l}\text { Weighted } \\
\text { Mean }\end{array}$ & $\begin{array}{l}\text { Verbal } \\
\text { Interpretation }\end{array}$ \\
\hline $\begin{array}{l}\text { 1. The grievance committee members provide feedback to the employee } \\
\text { about what can, and cannot be done to resolve the problems/issues. }\end{array}$ & 3.60 & Highly Observed \\
$\begin{array}{l}\text { 2. The grievance committee members clearly explain to a grievant when } \\
\text { there is little or no chance of winning a grievance. }\end{array}$ & 3.53 & Highly Observed \\
$\begin{array}{l}\text { 3. Managers/supervisors express their feelings and thoughts freely with } \\
\text { the complaint and the grievance committee members. }\end{array}$ & 3.40 & Observed \\
$\begin{array}{l}\text { 4. Managers/supervisors can express their feelings while on the meeting. } \\
\begin{array}{l}\text { 5. The employees are glad and happy to serve the customers and guests. } \\
\text { 6. The employees express their feelings freely about their grievances in }\end{array} \\
\text { front of the managers/supervisors. }\end{array}$ & 3.40 & $\begin{array}{l}\text { Highly Observed } \\
\text { Observed }\end{array}$ \\
\hline Composite Mean & $\mathbf{3 . 5 3}$ & Highly Observed \\
\hline
\end{tabular}


As presented in the table, the assessment of the respondents' with regard to their observation in the area of expressive are found highly observed as reflected to the statement "Managers/supervisors can express their feelings while on the meeting" has the highest weighted mean of 3.67 with an interpretation of "highly observed". It was followed by the statement, "The grievance committee members provide feedback to the employee about what can, and cannot be done to resolve the problems/issues" and "The employees express their feelings freely about their grievances in front of the managers/supervisors" with a weighted mean of 3.60 with an interpretation of "highly observed". The table also revealed that the statement which garnered the last rank was the statement "Managers/supervisors express their feelings and thoughts freely with the complaint and the grievance committee members" and "The employees are glad and happy to serve the customers and guests" as obtained to its weighted mean of 3.40 with an interpretation of "observed". Overall, the assessment on communication skills in handling hoteliers' grievances as to expressive garnered a 3.53 composite mean and has a verbal interpretation of "highly observed". The findings imply that the hotel establishment expressed their feelings toward grievances freely.

The finding got support from Lee-Savage (2010) who claimed that the establishment of a fixed customer service culture makes staff feel better able to deal with guest complaints by themselves, which in turn gives customers the satisfying feeling that their concerns are being personally addressed rather than filed away at corporate headquarters. "Empower staff so they are confident enough to be able to resolve the problem within the hotel rather than having to escalate the problem to head office. Providing a client with a new room, an upgrade or an after dinner drink shows the guest that you care about them.

3.2.4 Representative. This kind of speech act represents, the speaker's belief and carries the true or false value. The forces that fall into this category include stating, describing, reporting, confirming and so on (Searle, 1969). Table 4 presents the assessment on the communication skills in handling hoteliers' grievances in terms of representative.

Table 4. Communication Skills in Handling Hoteliers' Grievances as to Representative

\begin{tabular}{lll}
\hline Statements & Weighted Mean & $\begin{array}{l}\text { Verbal } \\
\text { Interpretation }\end{array}$ \\
\hline $\begin{array}{l}\text { 1. The grievance committee members determine if there is a violation } \\
\text { when it comes to Collective Bargaining Agreement (CBA). }\end{array}$ & 3.40 & Observed \\
$\begin{array}{l}\text { 2. The grievance committee members determine if the employee is a } \\
\text { victim of unfair treatment or actions of the company. }\end{array}$ & 3.53 & Highly Observed \\
$\begin{array}{l}\text { 3. Managers/supervisors have formal discussions of grievances with } \\
\text { the employees to learn how the contract should be interpreted and } \\
\text { what kind of settlement or adjustment to be made. }\end{array}$ & 3.40 & Observed \\
$\begin{array}{l}\text { 4. Managers/supervisors know about past grievance settlement of } \\
\text { similar nature as the grievance to be presented. }\end{array}$ & 3.40 & Observed \\
$\begin{array}{l}\text { 5. Employees determine if there are a genuine grievances and } \\
\text { whether the same is justified or not. }\end{array}$ & 3.40 & Observed \\
$\begin{array}{l}\text { 6. Employees are familiar with the Collective Bargaining Agreement } \\
\text { (CBA) and company personnel policy. }\end{array}$ & 3.47 & Observed \\
\hline Composite Mean & $\mathbf{3 . 4 3}$ & Observed \\
\hline
\end{tabular}

As shown in the table, the assessment of the respondents with regard to their observation in the area of representative are found observed as reflected to the statement "The grievance committee members determine if the employee is a victim of unfair treatment or actions of the company" has the highest weighted mean of 3.53 with an interpretation of "highly observed followed by the statement "Employees are familiar with the Collective Bargaining Agreement (CBA) and company personnel policy" with a weighted mean of 3.47 with an interpretation of "observed". The table also revealed that the rest of the statement garnered the last ranks which obtained its weighted mean of 3.40 with an interpretation of "observed". Therefore, the assessment on communication skills in handling hoteliers' grievances as to representative garnered a 3.43 composite mean and has a verbal interpretation of "observed". This implies that every employee on the hotel establishment must have a formal discussion about grievances and the settlement or adjustment to be made. The result is supported by Spelfogel (2016) who specified that when transaction is contemplated, in-house counsel and outside corporate counsel must consider all employment and labor implications of the transaction early in the planning process. 
Table 5. Summary of composite mean on communication skills in handling hoteliers' grievances.

\begin{tabular}{lcr}
\hline Communication Skills & Composite Mean & Verbal Interpretation \\
\hline Commissive & $\mathbf{3 . 5 9}$ & Highly Observed \\
Declarative & $\mathbf{3 . 4 9}$ & Observed \\
Expressive & $\mathbf{3 . 5 3}$ & Highly Observed \\
Representative & $\mathbf{3 . 4 3}$ & Observed \\
\hline Grand Composite Mean & $\mathbf{3 . 5 1}$ & Highly Observed \\
\hline
\end{tabular}

As shown in the table, the grand composite means of 3.45 indicates that the communication skills in handling hoteliers' grievances are highly observed. It can be gleaned that among the four (4) predetermined communication skills, commissive is the most relevant in dealing the individual communication skills having a highest composite mean of 3.59 with an interpretation of highly observed while representative is the least in dealing the individual communication skills having a lowest composite mean of 3.43 with interpretation of observed.

Table 6. Assessment on the difference analysis on the respondents' when grouped according to their Profile. It presents the significant difference on respondents' assessment when they are grouped according to their profile. The table includes the computed P-values at 5\% level of significance and the corresponding computed f-values.

Table 6. Difference analysis on the respondents' when grouped according to their Profile

\begin{tabular}{lllll}
\hline Profile Variables & Computed F-values & $\mathbf{p}$ values & $\begin{array}{l}\text { Decision } \\
\mathbf{H}_{\mathbf{0}}\end{array}$ & Interpretation \\
\hline Age & .668 & .531 & Failed to Reject & Not Significant \\
Gender & .140 & .714 & Failed to Reject & Not Significant \\
Civil Status & 2.287 & .144 & Failed to Reject & Not Significant \\
Position & 1.337 & .299 & Failed to Reject & Not Significant \\
Status of Employment & 2.578 & .117 & Failed to Reject & Not Significant \\
Role of Committee on Grievance & 2.578 & .117 & Failed to Reject & Not Significant \\
\hline
\end{tabular}

It can be gleaned from the table that when the assessment of respondents was grouped according to age, the pvalue of .531 was found greater than the level of significance of 0.05 , with computed f-values of .668 , thus the researchers failed to reject the null hypothesis that there is no significant difference on the assessment when grouped according to age.

Also, in terms of gender, the responses got the p-value of .714 having of computed f- values of .140 and were found greater than the level of significance of 0.05 , thus the researchers failed to reject the null hypotheses thus, there is no significant difference on the assessment when grouped according to gender.

In addition, the respondents' assessment was compared when they were grouped according to civil status, the pvalue of .144 was greater than $5 \%$ level of significance with computed f-values of 2.287 which direct the researchers to fail to reject the null hypothesis declaring that there is no significant difference between the respondents' assessment when grouped according to civil status.

While the position got a p-value of .299 which is greater than 0.05 level of significance with computed f-values of .1.337thus, the researchers failed to reject the null hypotheses thus, there is no significant difference on the assessment when grouped according to position.

Finally, with regard to status of employment, the responses got the p-value of .117 having of computed f- values of 2.578 and were found greater than the level of significance of 0.05 , thus the researchers failed to reject the null hypotheses that there is no significant difference on the assessment when groups according to status of employment.

Lastly, with regard to role of committee on grievance, the responses got the p-value of .117 having of computed f- values of 2.578 and were found greater than the level of significance of 0.05 , thus the researchers failed to reject the null hypotheses that there is no significant difference on the assessment when grouped according to role of committee on grievance. This means that the researchers failed to reject the null hypothesis and have to conclude that there is no significant difference between the assessments of the respondents when they are grouped according to their profile. 


\subsection{Proposed Courses of Action for Effective Communication Skills in Handling Grievances}

Based on the findings, the researchers proposed a course of action as input for effective communication skills in handling grievances, which includes area of concern, findings, objective, proposed action, person involved, and expected outcome.

\section{Conclusions}

Based on findings, the following conclusions appeared to be necessary: Since the majority of the respondents are male with age bracket of 24-38 years old married and with a regular permanent job and a member of grievance committee, it can be concluded that the employees are capable to communicate and handle employees grievances; The respondents' communication skills in handling hoteliers' grievances are found observed in terms of commissive, declarative, expressive and representatives, hence, the respondents are aware of handling grievances; since there is no significant difference between the assessment of the respondents in terms of age, gender, civil status, status of employment, position, and role of committee on grievance, the employee's profile had no bearing or no significant effect on their communication skills in handling hoteliers' grievances; and based on the results, the employees should be aware about the standard procedure implemented by their respective hotels which will help them to easily come up with the solutions when it comes to handling grievances.

\section{Recommendations}

In the light of foregoing findings and conclusions, the following recommendations are stated: The hotel establishments may conduct a seminar about handling grievances for their employees for them to know how to handle the complaints within the establishment and how to find better solution; the management may assess the communication skills or style with their employees in the establishment, and they should provide any kind of formal communication to build a harmonious relationship between other employees, supervisors, and manager; the management should maintain the freedom of employee when it comes to expressing what they feel in order to be transparent between the management; every employee on the hotel establishment may have a formal discussion about grievances and the settlement or adjustment to be made to determine what is right or true when handling grievances; and the future researchers may conduct further studies employing other variables that concern on how employees should handle grievances.

\section{References}

Aceron, R. M. (2015). Conversational Analysis: The Judge and Lawyers' Courtroom Interactions. Asia Pacific. Journal of Multidisciplinary Research, 3(5), 120127 December 2015 Part I.

Adams, A., \& Figueroa, J. (2013). Expediting settlement of employee grievances in the federal sector. Washington, D.C.: Office of the Chairman, Administrative Conference of the United States.

Anastasia. (2017). Effective Ways of Handling Employee Grievances. Retrieved on September 18, 2018 from https://www.cleverism.com/handling-employee-grievance/

Armstrong, T. (2008). The Human Odyssey Navigating the Twelve Stages of Life. New York, Sterling.

Dessler, G. (2013). Human Resource Management, ninth edition, Florida International University.

Flores, R. S. (2016). Oral Communication in Context. Rex Book Store, Inc.

Frost, S. (2008). Parenting and Education article.

Hartigan, J. (2013). 4 Steps to Handling Customer Complaints. Retrieved on September 23, 2018 from http://www.hotelnewsnow.com/Articles/17729/4-stepsto-handling-customer-complaints

Job Monkey. (2018). Types of Positions at Hotels. Retrieved on September 24, 2018 from http://www.jobmonkeyjobs.com

Kothari, C. R. (2008). Research Methodology: Methods and Techniques. New Delhi: New Age International Publishes.

Lee-Savage. (2010). Good Housekeeping: Coping with Complaints. Retrieved on September 26， 2018 from https://www.hotelmanagement network.com/features/feature94888/

Pathak, M. (2014). Benefits of Effective Communication in the Hotel Industry.

Robinson, I. (2010). Human Resource Management in Organization.

Sapungan, R. M., et al. (2018). Sociolinguistic Competence of Filipino Hotelier and Restaurateur Interns. International Linguistics Research, 1(2). ISSN 2576-2974 E-ISSN 2576-2982. https://doi.org/10.30560/ilr.v1n2p52 
Searle, J. R. (1969). Speech Acts. Cambridge: Cambridge University Press. https://doi.org/10.1017/CBO9781139173438

Serkan, H. (2014). Survey on the Communication Skills that the College Students of School of Physical Education and Sports Perceived from the Teaching Staff.

Spelfogel, E. J. (2016). Workforce Management Issues in Mergers and Acquisitions. Retrieved on November 4, 2018 from https://www.hospitalitylaboremploymentlawblog.com/articles/hotels/

Stanrock, J. S. (2008). Education Psychology, $3^{\text {rd }}$ Edition. New York: MC Graw Hill.

Stanrock, J. S. (2008). Grievance Committee Job Description. Retrieved on September 22, 2018 from http://www.rsar.net BylawsPolicies 9.8.11

\section{Copyrights}

Copyright for this article is retained by the author(s), with first publication rights granted to the journal.

This is an open-access article distributed under the terms and conditions of the Creative Commons Attribution license (http://creativecommons.org/licenses/by/4.0/). 